\title{
Correspondence
}

\section{Choice of feeding preparations for the newborn}

Sir,

Paediatricians have no particular expertise in selecting between humanised newborn formulas that fall within the prescribed safety guidelines of the Department of Health and Social Security, yet they are often asked to advise in choosing milk for the maternity units and children's wards of their hospitals. It is possible that their choice may be guided by doubtful incentives such as the label 'Made in Britain', the offer to sponsor the next unit meeting, or even the shape of the representative's legs. Milk is food for babies, and we would not wish to influence which weaning cereal or brand of cornflakes the hospital uses, so why their milk? Naturally, we should wish for a safe and nutritious product, but that apart, can we choose from the products available?

The natural outcome of such considerations is that the doctor should simply state which preparations are suitable for the newborn and that the district contract go out to competitive tender. When this happens, though protesting, the milk companies engage in a vigorous price cutting contest and may even offer their milk preparations free, to which the hospital finance officers react with glee. It is sad, however, that at present no savings achieved in this way are passed on to the department concerned and we still have to go to the Rotary Clubs to buy basic equipment such as ventilators and monitors.

It is of interest that in the January edition of Pediatrics Reiff and Essock-Vitale ${ }^{1}$ point out the subliminal influences of a hospital's choice of formulas in the mothers' selection of milk in bottle feeding her child. In acceding to the commercial choice we are therefore partisan by default.

Should we abdicate from the responsibilities of choosing a formula and leave it to the commercial forces? Should we insist that all suitable brands of milk are available at considerable cost to the health district? Or that the hospital milk be unbranded as Reiff and Essock-Vitale suggest? I would welcome comments.

\section{Reference}

1 Reiff MI, Essock-Vitale SM. Hospital Influences on early infant-fecding practices. Pediatrics 1985;76:872-9.

M F M BAMFORD

The Ipswich Hospital, Ipswich IP4 5PD,

England

\section{Catch up growth following abuse}

Sir,

As a Clinical Medical Officer working in a fairly deprived area of one of our largest cities, I was most interested to read the article by King and Taitz 'Catch up growth following abuse. "I was not sure, however, how one could utilise the information they present in following up an individual child at home. They state that one should watch for 'continuing growth failure at home', and that if there is not an 'early improvement in growth' with increasing social service input, serious consideration should be given to removing the child from home. How would the authors define these criteria?

In the group of children they studied, only 38 out of 95 had a height or weight below the third centile at presentation, so the remainder were presumably within 'normal' limits. The authors state that a child does not have to be less than the third centile to be failing to achieve his growth potential, but how does one prove that a child growing along the 10th, or even the third, centile could do better, especially if his parents are also small (even though this may be the result of abuse during their own childhood)?

Although they showed that there were more children among those removed from home who had catch up growth, what is to say that an individual child at home, if similarly placed, would not be among those children who did not show catch up? One could also argue that an adopted child whose growth was not improving was wrongly placed.

I fear that before 'continuing growth failure' is acted on it is still going to have to mean failure to grow so there is a falling away from the centiles, or an actual loss of weight.

\section{References}

' King JM. Taitz LS. Catch up growth following abuse. Arch Dis Child 1985;60:1152-4.

Juliet COURT

Plant Hill Clinic, Manchester 9 , England

Drs King and Taitz comment:

Dr Court is correct. Children whose growth is following the appropriate centile line cannot be construed as failing to thrive, irrespective of their position on the centile chart. We do not suggest otherwise in our paper. Failure to thrive due to child abuse can only be inferred in the following circumstances:

(1) Continued deviation on the centile chart while with natural parents;

(2) Deviation upward while in foster care.

Careful follow up of all abused children is vital.

What our paper shows is that the long term outlook for growth appears to be better in foster care. This adds to the case for the removal of some abused children but, as $\mathrm{Dr}$ Court implies, growth data based on a single value are uninterpretable. 